\title{
Long-term time-lapse geoelectrical monitoring
}

\author{
In this overview of research into geoelectrical monitoring at the British Geological Survey, \\ Paul Wilkinson," Jonathan Chambers, Oliver Kuras, Philip Meldrum and David Gunn \\ highlight the technology and algorithms that have been developed to investigate the \\ dynamics of landslide processes, the physical integrity of vulnerable earth structures, and the \\ thermal state of permafrost.
}

The British Geological Survey (BGS) has been researching the use of geoelectrical tomography to investigate the shallow subsurface for over two decades. In recent years, the development effort has been focussed on automated time-lapse geoelectrical monitoring of dynamic processes. This work has been undertaken by the Geophysical Tomography (GTom) Team (www.bgs.ac.uk/research/tomography), which comprises specialists in applied and theoretical geophysics, mathematics, and electronic engineering. The remit of the team covers the research, development and application of instrumentation, survey design, telemetry, data management, algorithms, modelling, data fusion, interpretation and delivery. This research is carried out for, and in collaboration with, a range of public, private and government sector organisations including Research Councils UK, the Technology Strategy Board, British Waterways, the Coal Authority, Network Rail, London Underground Ltd, and major corporations within the UK nuclear and defence sectors.

A major component of recent and ongoing GTom work is the BGS ALERT system. This enables the near real-time measurement of geoelectric, hydrologic and other properties 'on demand', thereby giving early warning of potential threats to vulnerable areas and sites. Permanent in-situ geoelectric measurements are used to provide surrogate indicators of hydrochemical and hydrogeological properties. The ALERT survey concept principally uses electrode arrays, permanently buried in shallow trenches or attached to borehole casings (Kuras et al., 2009; Ogilvy et al., 2009), although other sensor types can be incorporated to provide direct measurements for calibration. This network is then interrogated from the office by wireless telemetry (see Figure 1) to provide volumetric images of the subsurface at regular intervals. Once installed, data are transmitted automatically according to a pre-programmed schedule and for specific survey parameters, both of which may be varied remotely as conditions change. The entire process from data capture to visualization on the web-portal is automated and seamless. While similar concepts have been described before (Daily et al., 2004; Versteeg et al., 2006; Versteeg and Johnson, 2008), the ALERT system is fully

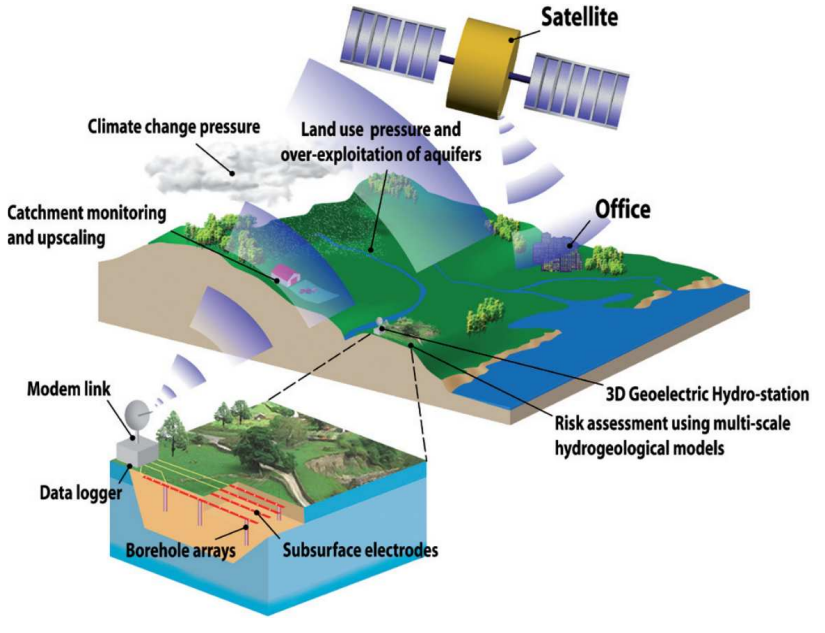

Figure 1 Schematic ALERT concept showing buried electrical resistivity tomography arrays and remote data transmission.

integrated in a single, field-hardened, water-proof sealed box, designed to withstand extreme conditions in remote localities. No PC is needed in the field. It has been designed for "install and walk-away" remote operation without further manual intervention.

GTom has previously used time-lapse Electrical Resistivity Tomography (ERT) to monitor the remediation of contaminated land (Wilkinson et al., 2010a), track anthropogenic pollutants and pathways (Chambers et al., 2010), monitor the exploitation of aquifers (Ogilvy et al., 2009), and assess dewatering operations during mineral quarrying (Chambers et al., 2011a). The timescales of these projects ranged between one and three years, with temporal resolutions of several hours to several days. In this paper we describe two ongoing ALERT monitoring projects; one to understand the dynamics and processes of an active landslide, and another to develop an early warning system to monitor the physical integrity of vulnerable earth structures in the transport network. These projects incorporate other recent GTom advances, specifically optimised survey design and electrode movement tracking using only resistivity data. We also highlight the 
First Break, 29, 77-84 (2011)

[The definitive version is available at www3.interscience.wiley.com]

development of a new system, which combines the ALERT monitoring concept with a novel non-contacting Capacitive Resistivity Imaging (CRI) technique developed at BGS (Kuras et al., 2006). This proof-of-concept project seeks to apply geoelectrical methodologies to the remote spatial and temporal monitoring of freezing and thawing permafrost.

\section{Landslide Monitoring}

ERT is widely used to investigate landslides (Jongmans and Garambois 2007), both to image failure surfaces (e.g. Lapenna et al., 2005) and, in time-lapse mode, to assess the effects of saturation (e.g. Jomard et al., 2007). In Spring 2008, we permanently installed an ALERT system to monitor an active landslide with the aim of revealing the hydrogeological precursors to movement.

The landslide site is near Malton, North Yorkshire, UK. It is located on a south facing valley side with a slope of approximately $14^{\circ}$. The bedrock geology, from the base to top of slope, comprises the Lias Group Redcar Mudstone Formation (RMF), Staithes Sandstone and Cleveland Ironstone Formation (SSF), and Whitby Mudstone Formation (WMF), which are overlain at the top of the hill by the Dogger

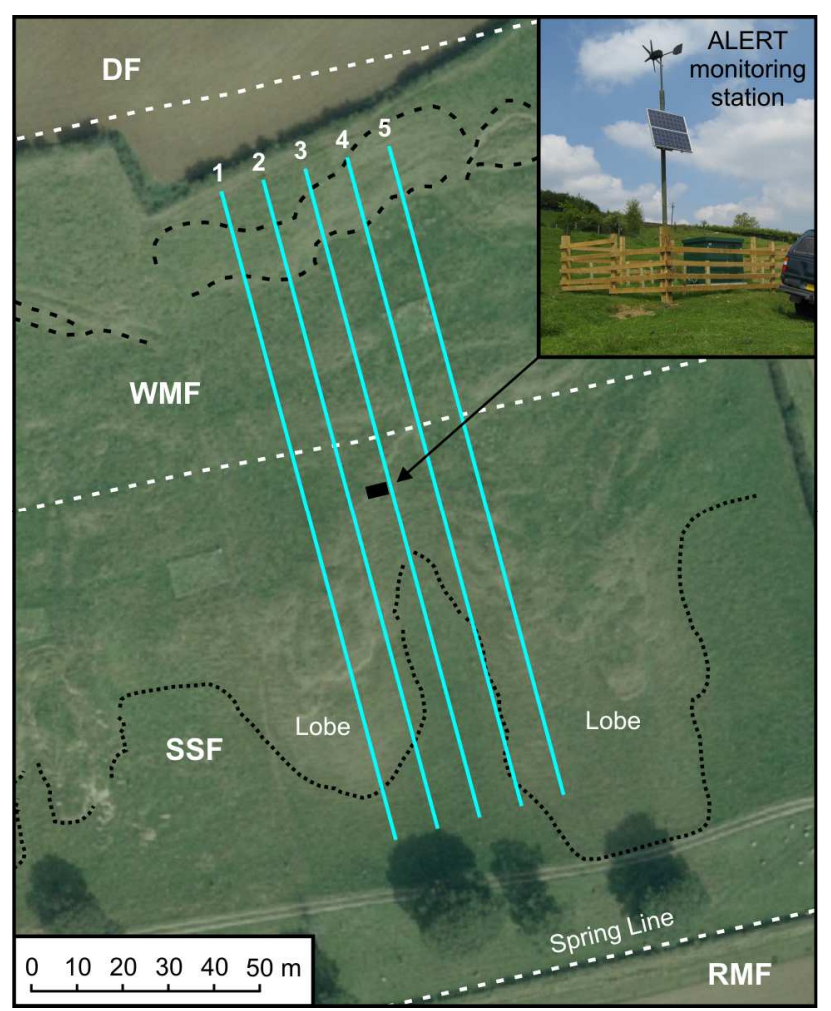

Figure 2 Site plan showing the location of the ALERT station, ERT monitoring arrays (blue lines, numbered), major geomorphologic features (top and base of the main scarp - black dashed lines; toe of the earth flows - dotted black lines) and bedrock geological boundaries (white dashed lines) between the Dogger (DF), Whitby Mudstone (WMF), Staithes Sandstone (SSF) and Redcar Mudstone (RMF) formations. (Aerial Photo (C) UKP/Getmapping Licence No. UKP2006/01)
Formation (DF) (see Figure 2). The bedrock is relatively flat lying with a gentle dip of a few degrees to the north (Chambers et al., 2011b). Slope failure at the site is occurring in the weathered WMF, which is highly prone to landsliding. The landslide is characterised by shallow rotational failures at the top of the slope that feed into larger-scale slowly moving lobes of slumped material, which extend approximately $150 \mathrm{~m}$ down the slope. The ALERT system is connected to five parallel electrode arrays running from the base to the top of the slope. Resistivity data are collected from the linear arrays, which each comprise 32 electrodes initially evenly spaced at $4.75 \mathrm{~m}$. The data are inverted using a regularised least-squares method as implemented in the Res2DInv / Res3DInv codes from Geotomo Software.

We are using a conventional dipole-dipole survey arrangement to monitor the landslide, but the system is also being used to test our research into automated optimal survey design. These optimised surveys give superior image resolution for the same number of measurements (Wilkinson et al., 2006a; 2006b; Loke et al., 2010), but research is ongoing into their practical application. The dipole-dipole and optimised example images shown in Figure 3 were obtained from line 4 (see Figure 2). Both exhibit resistivity variations consistent with the expected stratigraphic sequence. The boundary between the WMF and SSF has been inferred from the resistivity images and is clearly defined in each case. There is also a clear indication in both resistivity images of slipped WMF material
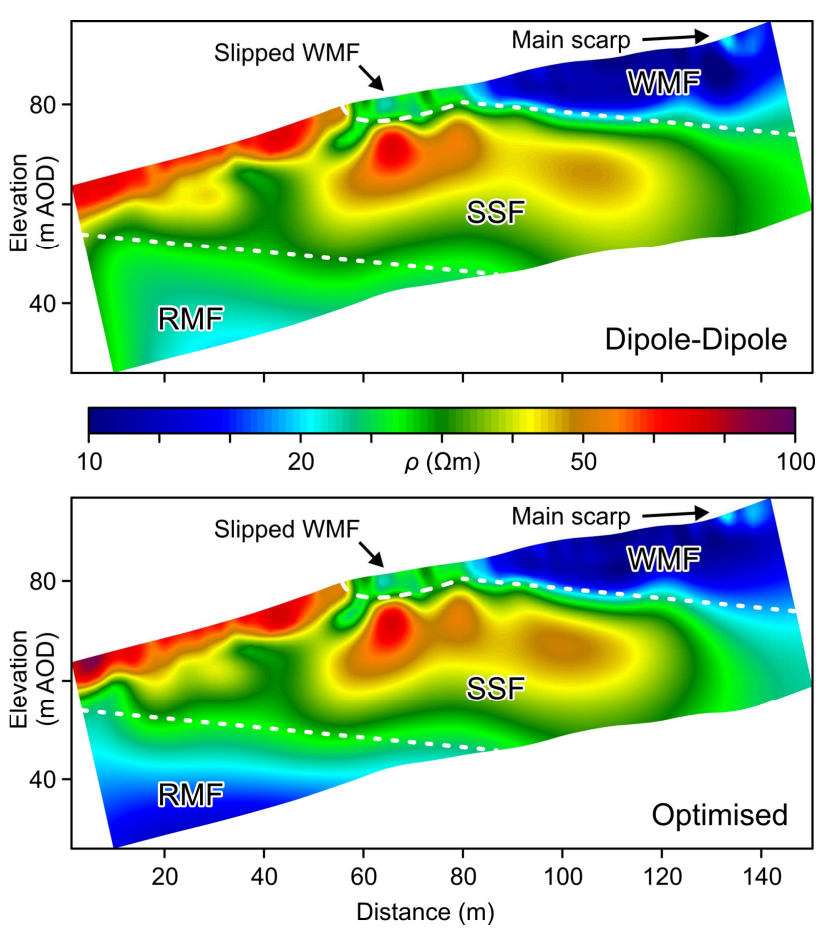

Figure 3 Inverted a) dipole-dipole and b) optimised images. The inferred boundaries between the WMF, SSF and RMF are shown by dashed white lines. The main scarp and slipped WMF material are indicated by arrows. 
First Break, 29, 77-84 (2011)

[The definitive version is available at www3.interscience.wiley.com]

overriding the more competent SSF. The lower boundary between the SSF and RMF has been positioned to be consistent with an auger hole log just to the south of line 3 . This boundary is not captured accurately in the dipole-dipole image, but is more clearly resolved in the optimised image. In general the contrasts of equivalent features are slightly improved throughout the model space in the optimised image compared to the dipole-dipole image.

ERT monitoring is particularly well suited to studying landslide processes since resistivity is sensitive to changes in saturation. But the measured potentials depend not only on the subsurface resistivity, but also on the positions of the electrodes. These are usually assumed to be known and fixed, but on an active landslide the electrodes will move over time, typically by about $2 \mathrm{~m} / \mathrm{y}$ in this case. If incorrect positions are used in the inversion (e.g. if the electrodes are not resurveyed after a period of movement) then artefacts will occur in the resulting image that can obscure genuine resistivity changes in the subsurface. We have developed a method to estimate the displacements of the electrodes solely from time-lapse resistivity data (Wilkinson et al., 2010b). This has enabled us to track their movements over a complete seasonal cycle without repeated manual resurveying of their positions. Briefly the method calculates the ratio of the resistivity data at the present time to the data at a baseline time when the electrode positions were known. The ratio data are fitted to a simple model which incorporates electrode movement and layered resistivity changes consistent with those caused by seasonal temperature variations. This model is inverted to yield the estimated electrode movements from their baseline positions. The algorithm currently only works in the longitudinal direction, and does not account for small-scale resistivity changes, but we have found that the predicted movements are accurate to within $4 \%$ of the unit electrode spacing. This is sufficient to track the electrodes over time and to correct any artefacts in the resistivity images caused by using the wrong positions. An

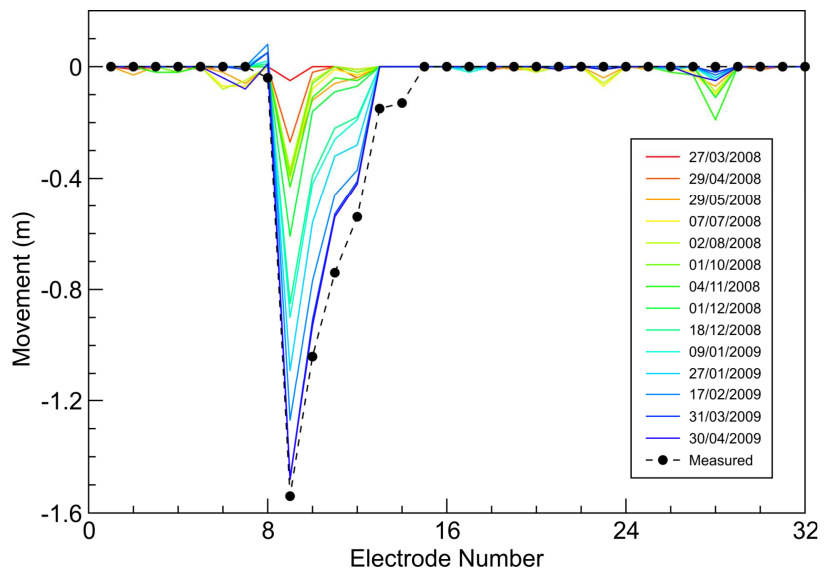

Figure 4 Predicted downslope electrode movements between March 2008 and May 2009. The measured positions in August 2009 are shown by filled circles. The electrode number increases to the north (i.e. up the slope). example of the predicted movements as a function of time is shown in Figure 4. The data were measured on line 1, which crosses one of the active lobes, for just over one year and the results match the expected seasonal behaviour (no movement during the spring and summer months, but significant activity during late autumn and winter). Our research is ongoing into combining resistivity and position inversion in a single model and incorporating lateral movement, both of which should improve the accuracy of the results.

Both of the techniques described here are being used in the ongoing monitoring of the landslide, its dynamics and its hydrogeological processes. The optimised survey designs provide improved image resolution, and the electrode tracking algorithm reduces image artefacts between manual electrode position surveys. The long-term goal is to produce calibrated 3D models of the subsurface moisture content variations from the time-lapse resistivity data. This will require laboratory analysis and modelling of the petrophysical resistivitysaturation and resistivity-temperature relationships, as described in the next example.

\section{Earthwork Stability Monitoring}

Transport earthworks, such as embankments, can be vulnerable to instability triggered by sustained wetting or drying events. The resilience of earth structures to these climatic stresses, particularly in the case of old waterway and railway embankments, can be difficult to determine due to the complexity of fill materials and the limitations of current approaches to characterisation and monitoring. However, recent research has shown that volumetric ERT imaging can be successfully applied to the investigation of these structures (Jackson et al., 2002; Sjodahl et al., 2006; Chambers et al., 2008), and that measures of saturation can be derived from temperature-corrected tomographic images (Brunet et al., 2010). We have deployed ALERT to monitor the long-term groundwater processes that drive progressive deterioration in a Victorian-era embankment. The results of the first trial phase have identified wetting and drying fronts penetrating deep into the structure.

The study site is located on a section of embankment between Nottingham and Loughborough, East Midlands, UK, on the former Great Central Railway which is currently used as a freight and heritage line. The embankment runs approximately north-south, and is located on a natural slope dipping a few degrees towards the west. In the area of the study site the embankment is approximately $5.5 \mathrm{~m}$ high and $30 \mathrm{~m}$ wide, and is constructed from end-tipped Westbury Formation Mudstone, sourced from a cutting situated less than $1 \mathrm{~km}$ to the south. Investigations at the site have demonstrated that the embankment is highly heterogeneous, due to the end-tipping technique used in its construction, comprising re-worked mudstone gravel of angular lithoclasts of the Westbury Formation with sporadic cobbles of Blue Anchor Formation 
First Break, 29, 77-84 (2011)

[The definitive version is available at www3.interscience.wiley.com]

(Gunn et al., 2008). The embankment rests on Branscombe Formation Mudstone bedrock.

Permanent ERT monitoring arrays have been installed within a $22 \mathrm{~m}$ section of the embankment as a series of twelve lines at $2 \mathrm{~m}$ intervals running perpendicular to the rails. Each line comprised 32 electrodes at $1 \mathrm{~m}$ intervals, running from the toe of the eastern flank to the toe of the western flank. The results presented here are from an individual 2D imaging line at $y=12 \mathrm{~m}$ located within the 3D imaging area $(y=0-22 \mathrm{~m}$, $x=0-31 \mathrm{~m})$. The data were collected using a dipole-dipole survey configuration and were inverted using Res2DInv.

To use resistivity images as a proxy for moisture content distributions, it is necessary to correct the images for temperature changes and to establish a relationship between resistivity and saturation. Multi-level temperature sensors were installed at the site to determine the subsurface seasonal temperature variations. Using a methodology similar to that of Brunet et al. (2010), the temperature data were fitted to a sinusoidal variation about a mean temperature with an amplitude that decreased exponentially with depth. The differences between the measured and modelled temperatures were typically $<1{ }^{\circ} \mathrm{C}$ within the depth range $0.5-5.5 \mathrm{~m}$. This model was used to correct the resistivity images to the mean annual temperature assuming that the resistivity decreases by $2 \%$ per $1{ }^{\circ} \mathrm{C}$ increase in temperature (Hayley et al., 2007).

To relate moisture content to resistivity, one can either employ established semi-empirical models such as Archie (1942), or use laboratory measurements as we have done here to determine an empirical relationship. Core samples were gathered via drilling sorties within the area of the study site. These were sub-sampled into $200 \mathrm{~mm}$ sections, which were used to determine a range of estimated values of porosity, density and moisture content for the fill and bedrock. Samples

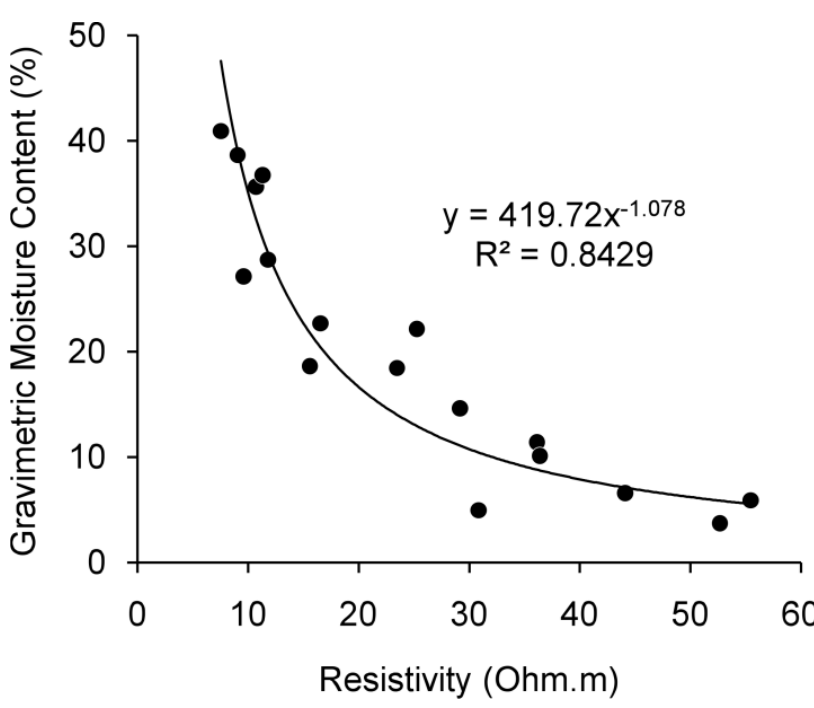

Figure 5 Variation in resistivity with gravimetric moisture content in laboratory samples derived from Westbury Mudstone Formation embankment material taken from the Great Central Railway test site.
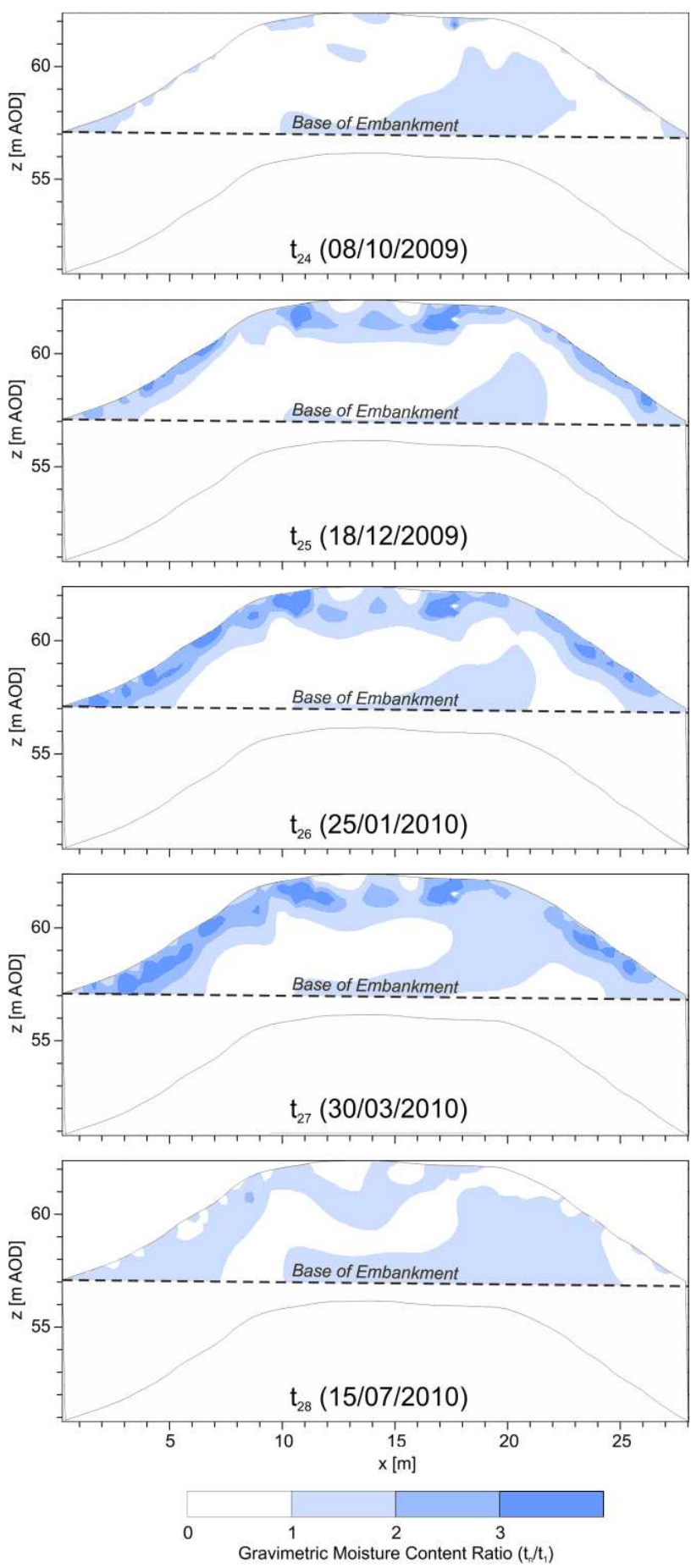

Figure 6 ERT-derived gravimetric moisture content ratio plots calculated using the resistivity moisture content relationships determined from laboratory testing.

were gently crushed to remove particles greater than $8 \mathrm{~mm}$ and re-saturated using distilled, deionised water to moisture contents ranging from below the shrinkage limit and up to the liquid limit - in practice this ranges from $5 \%$ to $40 \% \mathrm{w} / \mathrm{w}$. Resistivity measurements were made using a non-contacting 
First Break, 29, 77-84 (2011)

[The definitive version is available at www3.interscience.wiley.com]

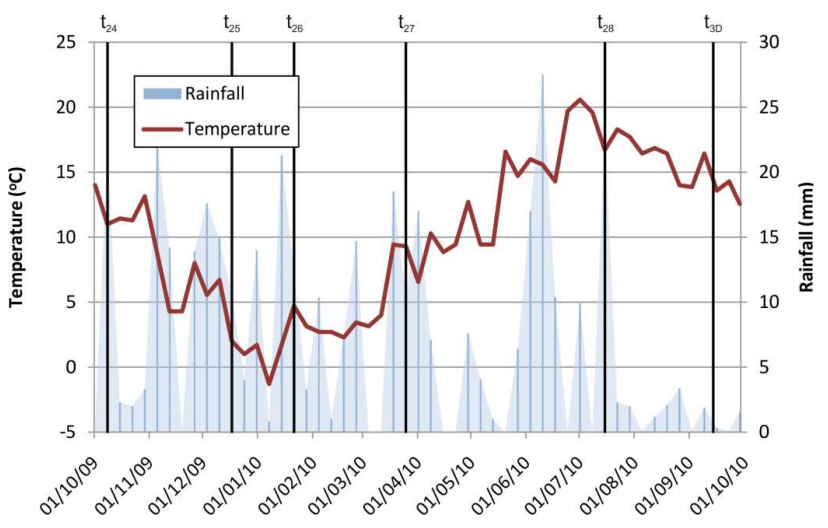

Figure 7 Weekly rainfall and mean air temperature records ( 8 $\mathrm{km}$ from the test site).

inductive logging tool (Jackson et al., 2006). The resulting relationship between resistivity and gravimetric moisture content is shown in Figure 5.

The ERT-derived temperature-corrected 2D moisture content ratio plots are shown in Figure 6 for a monitoring period between October 2009 and July 2010, which captures a complete seasonal wetting and drying cycle. The temporal variations, shown by the ratios of the gravimetric moisture to a baseline established in July 2006, indicate that the changes are concentrated predominantly in the upper $2 \mathrm{~m}$ of the flanks and crest. These images chart the development of a wetting front during the winter months (indicated by an increase in moisture content ratio) associated with higher rainfall, lower temperature lower evapotranspiration. For comparison, rainfall and air temperature records are shown in Figure 7.

In general, moisture levels are generally significantly below the liquid limit of the Westbury Mudstone Formation. The wettest zone $(30-40 \%)$ is in the core of the embankment within a layer between $\sim 2$ and $4 \mathrm{~m}$ below the crest (Chambers et al., 2011c). This zone persists throughout the summer and winter months, and is located in the clayey fill materials, which may retain moisture more effectively than the more granular overlying materials. Moisture contents associated with seasonal variations on the flanks and crest are relatively low $(<20 \%)$, indicating that significant instability on the flanks or crest is unlikely even during the wettest periods of the year.

\section{Permafrost Monitoring}

Both the landslide and earthwork monitoring studies rely on being able to make low resistance galvanic contacts between the electrodes and the ground. But this is not possible for certain geoscientific applications of ERT. GTom have therefore developed Capacitive Resistivity Imaging (CRI) technology, which uses non-contacting capacitive sensors to enable resistivity tomography when galvanic contact is not feasible (such as on dry or frozen ground) or where the installation of conventional galvanic electrodes is undesirable (such as on engineered surfaces). This technology, originally developed for one-off towed data acquisition (Kuras et al., 2007), is now being adapted for the routine spatial and temporal monitoring of permafrost, a key indicator of global climate change. The research is carried out in partnership with the Universities of Sussex and Bonn.

CRI is based upon a low-frequency, capacitively-coupled measurement approach (Kuras et al., 2006) and emulates ERT methodology, so that processing and modelling algorithms for conventional DC resistivity can be used. Recent work has shown that temperature-calibrated ERT using galvanic sensors is capable of imaging recession and re-advance of rock permafrost in response to the ambient temperature regime (Krautblatter and Hauck, 2007; Krautblatter et al., 2010). However, the use of galvanic sensors can lead to significant practical limitations on field measurements due to high contact resistances between the sensors and the host material, which also exhibit large changes as it freezes and thaws. Capacitive technology would overcome this problem and provide a more robust means of making high-quality resistance measurements with permanently installed sensors over time. Reducing uncertainty due to sensor noise is expected to increase the value of time-lapse ERT datasets for monitoring permafrost.

The present research applies 4D CRI (3D tomography with time) as well as conventional ERT to laboratory experiments simulating permafrost growth, persistence and thaw in bedrock. The Permafrost Laboratory at the University of Sussex is being used, which is a unique facility designed specifically to carry out large-scale rock freezing experiments. A methodology investigating the process of bedrock fracture by ice segregation was pioneered there (Murton et al., 2006), which forms the basis for our current experimental work. We expect temperature-calibrated geophysical imaging to provide new volumetric insight into, and quantitative control over, the evolution of permafrost in bedrock.

Water-saturated samples of limestone and chalk $(450 \mathrm{~mm}$ high, $300 \mathrm{~mm} \times 300 \mathrm{~mm}$ wide) of varying porosity are being

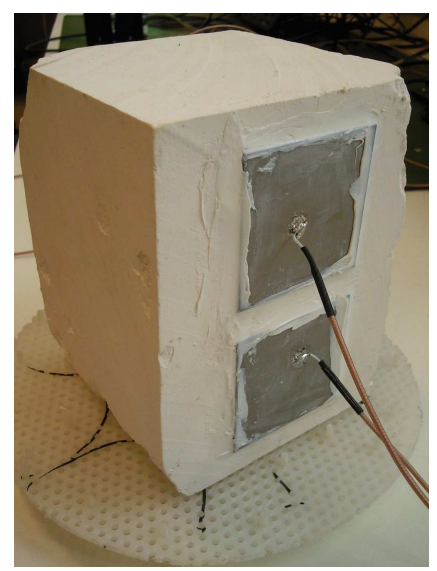

Figure 8 Sample of Newhaven Chalk instrumented with a four-plate capacitive sensor arrangement (two each on the near and far faces) to determine resistivity. 
First Break, 29, 77-84 (2011)

[The definitive version is available at www3.interscience.wiley.com]

monitored. The lower half of each sample is maintained at temperatures below $0^{\circ} \mathrm{C}$ (simulating permafrost) and the upper half is cycled above and below $0^{\circ} \mathrm{C}$ (simulating seasonal thawing and freezing of the overlying active layer). Samples are instrumented with both capacitive (Figure 8) and conventional galvanic sensor arrays in order to compare results between both resistivity methods. Time-lapse imaging of the samples during 10 successive freeze-thaw cycles of the active layer will test the functionality of the prototype instrumentation and provide representative CRI and ERT datasets. Experimental control and calibration of the resistivity images is being provided by simultaneous temperature and moisture content measurements on the sample.

4D CRI on a rock sample of limited size requires the use of dense capacitive sensor networks installed across the accessible surface areas of the sample. Besides the technical challenges of designing and constructing a practical system architecture that can utilise multi-sensor geometries for spatially distributed capacitive resistivity measurements, there were initial concerns about the feasibility of making accurate measurements with such dense arrays of capacitive sensors. Some potential pitfalls are:

- Our preferred CRI theoretical approach involves an idealised point sensor approximation. Mutual coupling between real sensors and stray capacitances might affect some complex transfer impedance measurements.

- The use of finite-size sensors to image a 3D volume of limited extent might cause geometric errors that could jeopardise the validity of the reconstruction and hence the effectiveness of the methodology.

- The expected sensor capacitances involved are very small (of the order of $20 \mathrm{pF}$ ), yet useful frequencies of operation lie in a range of $10-50 \mathrm{kHz}$. This poses particular challenges to the design of a capacitive current source.

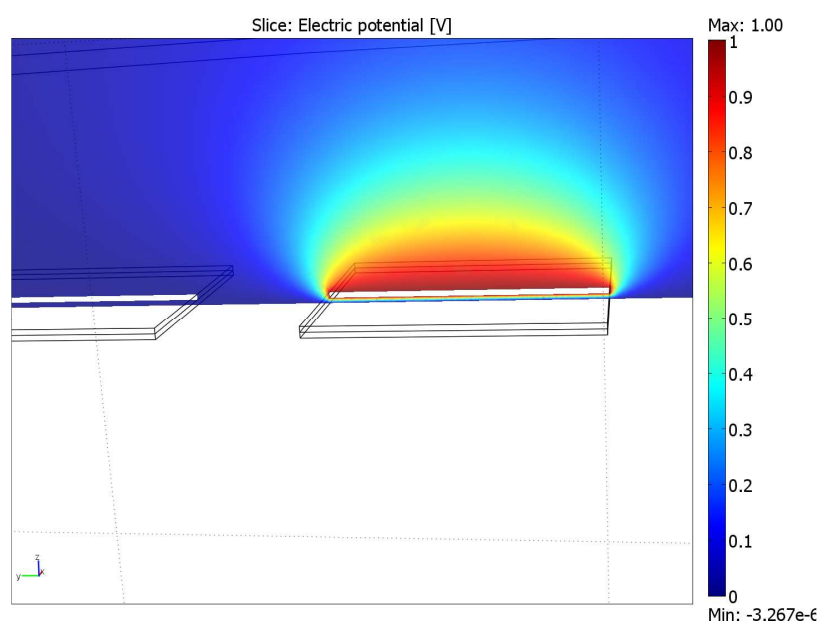

Figure 9 Model of a pair of neighbouring capacitive plates over a ground plane showing the distribution of electric potential in the $\mathrm{x}-\mathrm{z}$ plane.
In order to help us understand the behaviour of capacitive sensor networks, we have used COMSOL Multiphysics to simulate a capacitive plate over a ground plane. Typical sensor dimensions of $50 \mathrm{~mm} \times 50 \mathrm{~mm}$ were assumed, with the plate suspended at an elevation of $1 \mathrm{~mm}$ above the surface. A dielectric medium with $\varepsilon_{\mathrm{r}}=5$ was assumed to fill the intervening space, representing the material used to attach the sensor to the surface (e.g. silicone rubber).

We compared the capacitance of a single isolated plate over a ground plane with that of a plate in the immediate vicinity ( $25 \mathrm{~mm}$ separation) of another plate, which itself will act as a capacitive sensor (Figure 9). The two capacitances $(C=114.6 \mathrm{pF})$ agree with each other to within modelling accuracy indicating that mutual coupling is negligible. Other geometries and closer spacings are currently being investigated.

We have simulated 3D ERT imaging of rock samples with dense networks of electrodes, in order to test the sensitivity of such imaging geometries to the advance and recession of a strong temperature gradient (permafrost table). An array geometry with a total of 128 sensors, distributed across the four vertical faces of the sample, was employed. We expect to be able to use this geometry for capacitive as well as conventional DC measurements. Forward and inverse calculations were carried out for a range of vertical positions of the permafrost table, which was assumed to advance vertically as a flat plane throughout the sample. A scheme of bipole-bipole measurements was made across the sensor network, and resulting resistances were inverted to try and recover the position of the permafrost table. An example of an inverted model for a permafrost table at $90 \mathrm{~mm}$ from the top of the sample is shown in Figure 10.

Early results of this project have been encouraging and we are confident that the capacitive imaging technology will

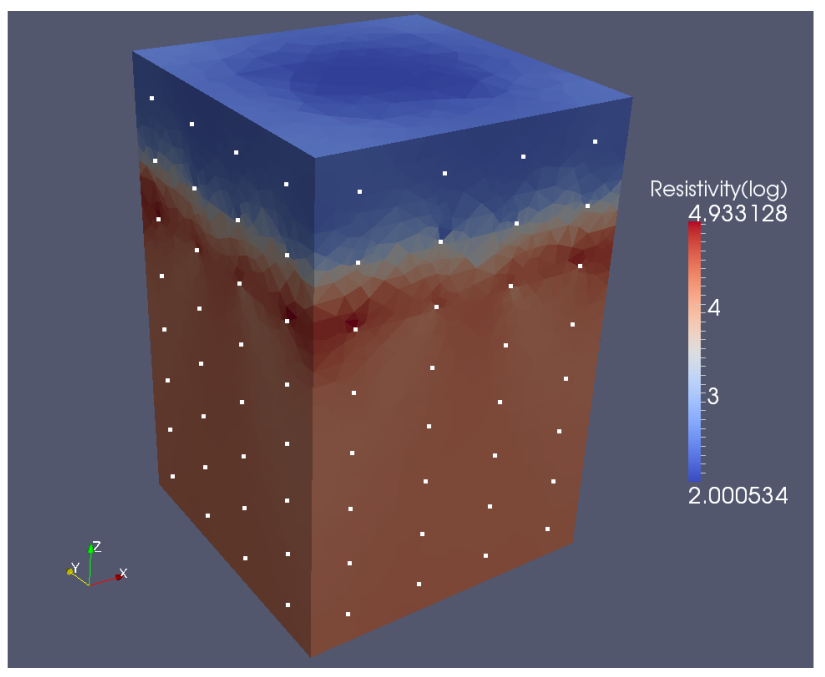

Figure 10 Inverted resistivity model of a rock sample (synthetic data) with an assumed permafrost table at a vertical distance of $90 \mathrm{~mm}$ below the top of the sample. 
First Break, 29, 77-84 (2011)

[The definitive version is available at www3.interscience.wiley.com]

usefully complement the DC resistivity imaging of permafrost rock samples. We expect that the methodology will allow us to obtain calibrated images of the temperature distribution in the sample during experiments simulating permafrost growth, persistence and thaw. The capacitive measurement principle should help to reduce the uncertainty in ERT monitoring data attributable to galvanic sensor noise, thus adding value to the geophysical monitoring of permafrost-affected rocks.

\section{Acknowledgements}

We thank our many collaborators within and outside BGS. Without their input and efforts the various projects highlighted in this paper would not have been possible. The Geophysical Tomography team was founded by Dr Richard Ogilvy and we are very grateful for his hard work, leadership and vision. Our investigations into optimised imaging and capacitive resistivity imaging are supported by Natural Environment Research Council Technology Proof of Concept grants NE/H00260X/1 and NE/I000917/1 respectively. Research and developments related to earthworks stability monitoring have been supported by the East Midlands Development Agency (emda) via the Single Programme fund, Project No. 06551. This paper is published with permission of the Executive Director of the British Geological Survey (NERC).

\section{References}

Archie, G. E. [1942] The electrical resistivity $\log$ as an aid in determining some reservoir characteristics. Petroleum Transactions of AIME, 146, 54-62.

Brunet, P., Clement, R. and Bouvier, C. [2010] Monitoring soil water content and deficit using Electrical Resistivity Tomography (ERT) - A case study in the Cevennes area, France. Journal of Hydrology, 380, 146-153.

Chambers, J. E., Gunn, D. A., Wilkinson, P. B., Ogilvy, R. D., Ghataora, G. S., Burrow, M. P. N. and Tilden Smith, R. [2008] Non-invasive time-lapse imaging of moisture content changes in earth embankments using electrical resistivity tomography (ERT). In: Ellis, E., Yu, H. S., McDowell, G., Dawson, A., and Thom, N. (Eds), Advances in Transportation Geotechnics, CRC Press, Boca Raton, 475-480.

Chambers, J. E., Wilkinson, P. B., Wealthall, G. P., Loke, M. H., Dearden, R., Wilson, R., Allen, D. and Ogilvy, R. D. [2010] Hydrogeophysical imaging of deposit heterogeneity and groundwater chemistry changes during DNAPL source zone bioremediation. Journal of Contaminant Hydrology, 118, 43-61.

Chambers, J. E., Wilkinson, P. B., Meldrum, P. I., Wardrop, D., Matthews, B., Penn, S., Joel, P., Aumonier, J., Weller, A. L., Benham, A. J., Bricker, S. H., Kuras, O., Cave, M. R. and Ogilvy, R. D. [2011a] Investigation and Monitoring of Aggregate Deposits Using Geo-Electrical Resistivity Imaging (IMAGER). British Geological Survey Commissioned Report, CR/11/001.

Chambers, J. E., Wilkinson, P. B., Kuras, O., Ford, J. R., Gunn, D. A., Meldrum, P. I., Pennington, C. V. L., Weller, A. L., Hobbs, P. R. N. and Ogilvy, R. D. [2011b] Three-dimensional geophysical anatomy of an active landslide in Lias Group mudrocks, Cleveland Basin, UK. Geomorphology, 125, 472-484.

Chambers, J. E., Gunn, D. A., Meldrum, P. I., Ogilvy, R. D., Wilkinson,
P. B., Haslam, E., Holyoake, S. and Wragg, J. [2011c] Volumetric imaging of earth embankment internal structure \& moisture movement as a tool for condition monitoring. Proc. 11th Int. Conf. Railway Engineering, London.

Daily, W., Ramirez, A., Newmark, R. and Masica, K. [2004] Low-cost reservoir tomographs of electrical resistivity. The Leading Edge, 23, 472-480.

Gunn, D. A., Reeves, H. J., Chambers, J. E., Ghataora, G., Burrow, M., Weston, P., Lovell, J. M., Nelder, L., Ward, D. and Tilden Smith, R. [2008] New geophysical and geotechnical approaches to characterise under utilised earthworks. In: Ellis, E., Yu, H. S., McDowell, G., Dawson, A., and Thom, N. (Eds), Advances in Transportation Geotechnics, CRC Press, Boca Raton, 299-305.

Hayley, K., Bentley, L. R., Gharibi, M. and Nightingale, M. [2007] Low temperature dependence of electrical resistivity: Implications for near surface geophysical monitoring. Geophysical Research Letters, 34, L18402.

Jackson, P. D., Northmore, K. J., Meldrum, P. I., Gunn, D. A., Hallam, J. R., Wambura, J., Wangusi, B. and Ogutu, G. [2002] Noninvasive moisture monitoring within an earth embankment - a precursor to failure. NDT \& E International, 35, 107-115.

Jackson, P. D., Lovell, M. A., Roberts, J. A., Schultheiss, P. J., Gunn, D. A., Flint, R. C., Wood, A., Holmes, R. and Frederichs, T. [2006] Rapid non-contacting resistivity logging of core. In. Rothwell, R.G. (Ed.), New techniques in sediment core analysis. Geol. Soc. Special Publ. SP 267.

Jomard, H., Lebourg, T., Binet, S., Tric, E. and Hernandez, M. [2007] Characterization of an internal slope movement structure by hydrogeophysical surveying. Terra Nova, 19, 48-57.

Jongmans, D. and Garambois, S. [2007] Geophysical investigation of landslides: a review. Bull. Soc. Géol. Fr., 178, 101-112.

Krautblatter, M. and Hauck, C. [2007] Electrical resistivity tomography monitoring of permafrost in solid rock walls. Journal of Geophysical Research - Earth Surface, 112, F02S20.

Krautblatter, M., Verleysdonk, S., Flores-Orozco, A. and Kemna, A. [2010] Temperature-calibrated imaging of seasonal changes in permafrost rock walls by quantitative electrical resistivity tomography (Zugspitze, German/Austrian Alps). Journal of Geophysical Research - Earth Surface, 115, F02003.

Kuras, O., Beamish, D., Meldrum, P. I. and Ogilvy, R. D. [2006] Fundamentals of the capacitive resistivity technique. Geophysics, 71, G135-G152.

Kuras, O., Meldrum, P. I., Beamish, D., Ogilvy, R. D. and Lala, D. [2007] Capacitive resistivity imaging with towed arrays. Journal of Environmental and Engineering Geophysics, 12, 267-279.

Kuras, O., Pritchard, J., Meldrum, P. I., Chambers, J. E., Wilkinson, P. B., Ogilvy, R. D. and Wealthall G.P. [2009] Monitoring hydraulic processes with Automated time-Lapse Electrical Resistivity Tomography (ALERT). Comptes Rendus Geosciences, 341, 868885.

Lapenna, V., Lorenzo, P., Perrone, A., Piscitelli, S., Rizzo, E. and Sdao, F. [2005] 2D electrical resistivity imaging of some complex landslides in the Lucanian Apennine chain, southern Italy. Geophysics, 70, B11-B18.

Loke, M. H., Wilkinson, P. B. and Chambers, J. E. [2010] Fast computation of optimized electrode arrays for 2D resistivity surveys. Computers \& Geosciences, 36, 1414-1426.

Murton, J. B., Peterson, R. and Ozouf, J. C. [2006] Bedrock fracture by ice segregation in cold regions. Science, 314, 1127-1129.

Ogilvy, R. D., Kuras, O., Meldrum, P. I., Wilkinson, P. B., Gisbert, J., 
First Break, 29, 77-84 (2011)

[The definitive version is available at www3.interscience.wiley.com]

Jorreto, S., Frances, I. and Pulido Bosch, A. [2009] Automated time-Lapse Electrical Resistivity Tomography (ALERT) for monitoring Coastal Aquifers. Near Surface Geophysics, 7, 367375.

Sjodahl, P., Dahlin, T. and Zhou, B [2006] 2.5D resistivity modeling of embankment dams to assess influence from geometry and material properties. Geophysics, 71, G107-G114.

Versteeg, R. J., Richardson, A. N. and Rowe, T. [2006] Web-accessible scientific workflow system for performance monitoring. Environmental Science \& Technology, 40, 2692-2698.

Versteeg, R. and Johnson, T. [2008] Using time-lapse electrical geophysics to monitor subsurface processes. The Leading Edge, 27, 1488-1497.

Wilkinson, P. B., Meldrum, P. I., Chambers, J. E., Kuras, O., and Ogilvy, R. D. [2006a] Improved strategies for the automatic selection of optimized sets of Electrical Resistivity Tomography measurement configurations. Geophysical Journal International, 167, 1119-1126.

Wilkinson, P. B., Kuras, O., Meldrum, P. I., Chambers, J. E. and Ogilvy, R. D. [2006b] Comparison of the spatial resolution of standard and optimised electrical resistivity tomography arrays. Proc 12th EAGE Near Surface Geophysics Conf, Helsinki.

Wilkinson, P. B., Meldrum, P. I., Kuras, O., Chambers, J. E., Holyoake, S. J. and Ogilvy, R. D. [2010a] High-resolution Electrical Resistivity Tomography monitoring of a tracer test in a confined aquifer. Journal of Applied Geophysics, 70, 268-276.

Wilkinson, P. B., Chambers, J. E., Meldrum, P. I., Gunn, D. A., Ogilvy, R. D. and Kuras O. [2010b] Predicting the movements of permanently installed electrodes on an active landslide using timelapse geoelectrical resistivity data only. Geophysical Journal International 183, 543-556. 